\title{
Retractable Syringes in a Swiss Prison Needle and Syringe Exchange Program: Experiences of Drug-using Inmates and Prison Staff Perceptions
}

\author{
Javier Barro • Alejandra Casillas • Laurent Gétaz • \\ Jean-Pierre Rieder • Mariem Baroudi • Anne François • \\ Barbara Broers • Hans Wolff
}

Published online: 17 April 2014

(C) Springer Science+Business Media New York 2014

\begin{abstract}
Needle and Syringe Exchange Programs (NSP) prevent infectious diseases in community and prisons. Less than $1 \%$ of prisons worldwide have NSP. One barrier is organizational concern for needle stick injuries from used syringes. Given these concerns, we introduced retractable syringes into our prison NSP and evaluated 1) injection drug users' experiences with retractable syringes and 2) beliefs and knowledge about NSP among prison officers (PO) and healthcare staff (HS). In 2010, we replaced usual syringes with retractable needle devices in the prison of Champ-Dollon, Geneva, Switzerland. We examined demographics, clinical profiles and NSP use among NSP participants, and asked about ease and safety of retractable syringes use in interviews. We distributed questionnaires to PO and HS, to assess knowledge and general opinions on NSP. The majority of participants expressed that retractable syringes were acceptable alternatives, but needed improvements. Of the questionnaires, $90.3 \%$ of PO and $9.6 \%$ of HS were still concerned about misuse of soiled syringes as weapons. Improving the quality and ease of use of use may increase the acceptance of retractable syringes. Continuing to address PO and HS safety concerns is an important step towards more disseminated NSP implementation and useful innovation.
\end{abstract}

Keywords Needle and syringe exchange program $\cdot$ Retractable syringe $\cdot$ Harm reduction $\cdot$ Prison

J. Barro $\cdot$ A. Casillas $\cdot$ L. Gétaz $\cdot$ J.-. Rieder $\cdot$ M. Baroudi $\cdot$ H. Wolff

Division of Penitentiary Medicine, Department of Community Medicine

and Primary Care and Emergencies, University Hospitals of Geneva, Geneva, Switzerland

J. Barro $\cdot$ A. Casillas $\cdot$ L. Gétaz $\cdot$ J.-. Rieder $\cdot$ M. Baroudi $\cdot$ A. François $\cdot$ B. Broers $\cdot$ H. Wolff

University of Geneva, Geneva, Switzerland

A. François $\cdot$ B. Broers

Dependencies Unit, Department of Community Medicine, Primary Care and Emergencies,

University Hospitals of Geneva, Geneva, Switzerland

J. Barro $(\bowtie)$

Service de médecine pénitentiaire, DMCPRU, 9ème étage, bureau 7A-9-731.3, Site Cluse Roseraie, Rue Gabrielle Perret Gentil 4, CH 1211 Genève 14, Switzerland

e-mail: Javier.Barro@hcuge.ch 


$\begin{array}{ll}\text { Abbreviations } \\ \text { NSP } & \text { Needle and syringe exchange program(s) } \\ \text { BBV } & \text { Blood borne virus } \\ \text { HIV } & \text { Human immunodeficiency virus } \\ \text { HBV } & \text { Hepatitis B virus } \\ \text { HCV } & \text { Hepatitis C virus } \\ \text { IDU } & \text { Injection Drug User(s) } \\ \text { IV } & \text { Intravenous } \\ \text { HS } & \text { Healthcare staff } \\ \text { PO } & \text { Prison officer(s) }\end{array}$

\section{Injection Drug Use — a Commonality Among Prisoners}

Injection drug use in prison carries a high risk for infection with blood-borne viruses (BBV) that contribute to a high degree of morbidity and mortality-human immunodeficiency virus (HIV), hepatitis B (HBV) and hepatitis C virus (HCV) (Stark et al. 2006). Additionally, transmission of BBV in prison is a growing crisis worldwide due to the increased imprisonment of individuals who are users or who deal drugs, and the overcrowding of prisons in many settings. Time in prison is common for injection drug users (IDU) given the illegality of drug use and criminal behavior due to the high price of drugs on the black market (Office Fédéral de la Statistique 2010; Jürgens et al. 2009): 56-90 \% of drug users have been imprisoned at least once in their lifetime, and drug use before imprisonment has been reported by up to $73 \%$ of all prisoners (European Monitoring Centre for Drugs and Drug Addiction 2011a, b; Jürgens et al. 2011). Studies in the US have shown that $80 \%$ of detainees had a history of drug use, with $20 \%$ of them identifying as IDU, and $12 \%$ reporting current injection use at the time of their arrest (CDC and Centers for Disease Control and Prevention 2001; Mumola, 1999; Thiede et al. 2001).

\section{Risks of Intravenous Drug Use in Prison}

Despite efforts to eradicate drug use or trafficking in prison, prisoners manage to attain access to illegal drugs; up to a third of prisoners engage in first-time use during incarceration (European Monitoring Centre for Drugs and Drug Addiction 2011a, b; Todts et al. 2007; Jürgens, 2007). The risk of BBV in prisons is amplified due to the large number of IDU who continually inject in this unique setting, where, the population is constantly changing and composed of individuals from different places- resulting in a higher number of injecting partners from diverse communities (Dolan et al. 2003).

Prison stays are also associated with behaviors that compound infectious risks linked to drug use. Prison drug users often take too little time to bleach their equipment correctly, and consume drugs quickly for fear of being caught. As well, the scarcity of sterile injection material among prisoners promotes sharing (European Monitoring Centre for Drugs and Drug Addiction 2004; Dolan, 2000; Lines et al. 2006). Scarce equipment compels prisoners infected with HIV and HCV to keep their condition secret, yet continue sharing tainted material (Bruce and Schleifer 2008). In the absence of harm reduction measures, incarceration is an independent risk factor for hepatitis C among drug users (Global Comission on Drug Policy 2013). 
Use of tainted injecting equipment in prison has also been found to be the most significant risk factor for HIV infection (Jürgens et al. 2009; Larney, 2010).

\section{Needle and Syringe Programs (NSP) as an Effective Harm Reduction Measure in Prison}

One important intervention has been the provision of clean injecting equipment through needle and syringe programs (NSP) to reduce unsafe injecting. NSP started out in an Amsterdam community setting in 1981 due to a HBV outbreak among injection drug users (Wodak and Cooney 2006), and programs have been implemented in more than 80 countries since then (Harm Reduction International 2010). Many studies have demonstrated the efficiency of NSP to reduce transmission of blood-borne diseases (especially HIV), highlighting its costeffectiveness and its ability to streamline direct access to support services for drug users (Harm Reduction International 2010; World Health Organization 2004; Degenhardt et al. 2010).

The evidence available from the few existing prison NSP suggests that their benefits are similar to community programs, and there is no valid suggestion to date, that these programs are unsafe or increase drug use (Wodak and Cooney 2006). NSP started in Swiss prisons in 1992, and the 1994 pilot Hindelbank program showed near-elimination of shared injection equipment after 1 year, and decreased new BBV infections over time (Dolan et al. 2003). NSP have also been shown to be effective in reducing HIV infections in prison among 10 systematic HIV evaluations (Jürgens et al. 2009, 2011). Evaluations in prison show that they do not lead to increased injection drug use (Stark et al. 2006); nor are they used as weapons against prison officers or other inmates (Dolan, 2000), or cause health issues for prison workers (Mogg and Levy 2009). Finally, prison NSP encourages the transition of IDU to drug rehabilitation and addiction programs (Jürgens et al. 2009, 2011).

WHO recommends that "prison authorities in countries experiencing or threatened by an epidemic of HIV infections among IDU should introduce NSP urgently and expand implementation to scale as soon as possible" (Harm Reduction International 2010; Mogg and Levy 2009). Still, only 60 prisons in 10 countries have implemented such programs. Different political and perceived risk barriers related to these programs stand in the way of sustainability and continued implementation. One example is Germany, where despite the success of seven prison programs by 2000 , the majority closed due to decisions by the newly elected conservative state governments despite protest from prison staff (Jürgens et al. 2011). Even in Switzerland, where harm reduction is part of official drug policy, only 13 of the 115 prisons have instituted NSP.

Fears and Barriers Surrounding NSP — a Motivation for Retractable Devices

Because there is public worry regarding inappropriate syringe disposal and the perceived risk to the wider community due to needle stick injury, replacing current injecting equipment distributed by NSP with retractable syringes/needles, has been a tried method in community settings (although difficult to assess the level of impact, given the low risk of BBV infection following needle-stick injury in the community) (Wodak and Cooney 2006; Kermode et al. 2003). A retractable device is made up of a needle and syringe where the needle retracts inside the barrel when the plunger is automatically/manually completely pushed down. Originally developed to decrease the number of needle-stick injuries in hospitals, one university hospital study did show decreased needle-stick injuries by $49 \%$ (Whitby et al. 2008). In this study, we aimed to assess acceptability and safety of retractable syringes with filters for NSP among 
IDU, and perceptions regarding NSP between prison officers (PO) and healthcare staff (HS) working in the prison of Champ-Dollon in Geneva, Switzerland.

We know that drug user acceptance is critical for the successful implementation of any new injection equipment (Des Jarlais, 1998), and also that views of prison stakeholders must be taken into account to fully integrate NSP (Mogg and Levy 2009). Our study is unique for two reasons: this is the first time that a trial of retractable devices in a prison NSP was conducted with injection drug users as active collaborators, and as well, we described the perceptions of prisoner officers and healthcare staff regarding general NSP.

\section{Methods}

\section{Setting}

This observational study took place in Switzerland's largest pre-trial prison (Champ-Dollon, Geneva), with a capacity for 376 detainees. The prison is overcrowded and had a mean occupation rate of $162 \%$ in 2010 (Wolff, 2010). One-third has consumed heroin or cocaine at least once in their life. Forty percent of detainees have consumed illegal drugs within 30 days of detention. Hepatitis $\mathrm{C}$ is diagnosed in $5.6 \%$ of the inmates, chronic hepatitis $\mathrm{B}$ in $1 \%$ and HIV in $1 \%$ (Wolff et al. 2011).

Prison health care is based on the Swiss drug policy, which relies on the four pillars model (prevention, treatment, harm reduction and repression) (Federal authority of the Swiss Conferederation, 2011). The harm reduction arm consists of a targeted approach towards drug users, and relies on proven measures like NSP, distribution of condoms with safe sex recommendations, opioid substitution treatment programs (OST) and heroin prescription programs (Addiction Suisse, 2013). NSP started in Champ-Dollon's prison in 1996, but state authorities gave formal authorization in 2000 .

\section{Program Intervention}

From April to November 2010, we replaced conventional 1-ml-insulin syringes contained in the "Flash Box", used in community NSP and traditional prison NSP, with retractable syringes developed by Unilife. These retractable syringes contained a mechanism allowing for manual control of needle retraction by the user. In community needle exchange facilities in Switzerland, syringes with built-in filters are usually provided, and so Unilife developed (at our request) an adaptor for those filters.

Each IV drug user entering the prison was informed during a systematic screening process of the existence of the needle and syringe exchange program. Patients were notified that they could request injection equipment from the healthcare staff (HS). If material was requested, they were invited to the prison medical unit for a confidential consultation aiming to explain the NSP procedure, and also to discuss practical issues related to drug use. The functioning of all equipment was explained at this visit and prevention and harm risk reduction messages were provided. Participating inmates gave written, informed consent and agreed to provide feedback about their experiences, particularly the introduction of the retractable syringes, as well as to include their clinical and demographic information. They were informed that a study nurse would contact him/ her to conduct a short demographic interview (first part) and evaluation about the experience (second part). 


\section{IDU Evaluation}

A short first interview was conducted with the study nurse to collect nationality, verify identification number and age, type of incarceration, duration of injection drug use, primary language spoken, and confirm consent.

Interview questions on client perception and satisfaction for the patient evaluation of the NSP were created in collaboration with addiction specialists and prison health care workers who have worked in NSP and participated in NSP improvement measures. The study nurse called patients back for questions after 2 to 3 weeks of trial use. Eleven statements focusing on the introduction of retractable syringes and its usability/acceptability were addressed in the interview with answer options being "strongly agree," "agree," "neither agree nor disagree," "disagree," and "strongly disagree." Patients were also allowed to qualitatively elaborate on their responses. For these analyses, patients who "strongly agreed" or "agreed" were counted as agreeing to the statement.

\section{Prison Officer (PO) and Healthcare Staff (HS) Questionnaire}

For a more general overview of perceptions about NSP from the prison and medical staff perspective, we distributed a written, self-administered questionnaire to all PO and HS. Again, interview questions were developed in collaboration with addiction specialists and prison health care workers who have worked in NSP and participated in NSP improvement measures. On one study day, we distributed 100 anonymous questionnaires to all prison and medical workers with prisoner contact. The questionnaire titled "Infectious Disease Questionnaire" included 14 statements focusing on knowledge and perceptions about drug use, infectious diseases transmission, harm reduction and NSP. Answer options were "not at all", "no", "yes", and "absolutely." Respondents were also allowed to qualitatively elaborate on their responses. For these analyses, "yes" and "absolutely" responses were counted together versus "not at all" and "no."

Analysis

Descriptive analyses concerning demographics, clinical profiles and interviews responses were carried out for the IDU. We describe PO and HS agreement to questionnaire statements.

The study received approval by the ethical commission for research of the Geneva University Hospitals (CER 09-016).

\section{Results}

Characteristics of NSP Participants (Table 1)

The average age of the 28 NSP participants was 32 years, with 27 of them being male. Most of the participants were from Eastern Europe (75\%). About $4 \%$ of the participants were HIVpositive and $32.1 \%$ had never been screened. We found one case of abscess at the injecting point during the study period.

\section{Equipment Distribution}

From April to November 2010, 284 retractable devices were distributed to 28 of 2,050 inmates in the Champ-Dollon prison. Overall, 201 syringes were returned for exchange, yielding a 
Table 1 Characteristics of initial NSP participants $(n=28)$

\begin{tabular}{|c|c|}
\hline Demographics & Mean (SD), range or N (\%) \\
\hline Age (years) & $31.2(4.8), 21-42$ \\
\hline Male & $27(96.4)$ \\
\hline Nationality & N (\%) \\
\hline Algeria & $2(7.1)$ \\
\hline Armenia & $1(3.6)$ \\
\hline Bosnia-Herzegovina & $1(3.6)$ \\
\hline Chile & $1(3.6)$ \\
\hline France & $3(10.7)$ \\
\hline Georgia & $13(46.4)$ \\
\hline Lithuania & $1(3.6)$ \\
\hline Romania & $2(7.1)$ \\
\hline Russia & $3(10.7)$ \\
\hline Ukraine & $1(3.6)$ \\
\hline Detentions and injection use & Mean (SD), range \\
\hline Time (weeks) of detention & $12.3(24.6), 0-115$ \\
\hline Number of incarcerations & $4.6(8.4), 1-45$ \\
\hline Length (days) of overall incarceration & $125.5(170.4), 5-690$ \\
\hline Time (months) of injection use & $92.9(88.7), 0-324$ \\
\hline Infection history & $\mathrm{N}(\%)$ \\
\hline HIV- positive, negative, unknown & 1 (3.6), 18 (64.3), 9 (32.1) \\
\hline HBV- positive, remission, negative, unknown & 2 (7.1), 5 (17.9), 12 (42.9), 9 (32.1) \\
\hline HCV- positive, remission, negative, unknown & 17 (60.7), 1 (3.6), 3 (10.7), 7 (25) \\
\hline Injection site abscess- yes, no, unknown & 1 (3.6), $24(85.7), 3$ (10.7) \\
\hline
\end{tabular}

return rate of $70 \%$. Health care workers observed that the filters, adapters and ascorbic acid distributed with the syringes were frequently returned unused (safety filters were not being used). Disassembled syringes were also found in the returned syringes, prompting the supposition that the engineered spring of the mechanism was used for other purposes.

\section{IDU Experiences (Table 2)}

Of the 28 who inquired about NSP, 26 inmates agreed to continue in the study and had the first interview encounter. However, 13 inmates were released before having the second interview (which evaluated the retractable syringes in the NSP). Of the 13 remaining participants, only ten had actually used the syringes and continued with the second interview (three were released before receiving their first syringe). Of note, there were no significant differences in terms of demographics and clinical profiles between the 28 initial participants and the 10 participants who completed the study. Of the ten participants who completed the study, six $(60 \%)$ agreed that retractable syringes are a useful tool, particularly adapted for prison settings; nine (90\%) agreed on the fact that using retractable NSP devices helps to protect others from potential infectious disease. They noted that retractable syringes were not more difficult to use, but that preparation and injection process took more time $(60 \%)$. All agreed that the mechanism worked well, with some differing opinions concerning its efficiency as 
Table 2 IDU responses about retractable syringes

\begin{tabular}{|c|c|c|c|c|c|}
\hline \multirow[t]{2}{*}{ Questionnaire Statement } & \multirow{2}{*}{$\begin{array}{l}\text { Strongly } \\
\text { Agree } \\
\text { N }(\%)\end{array}$} & \multirow{2}{*}{$\begin{array}{l}\text { Agree } \\
\mathrm{N} \\
(\%)\end{array}$} & \multirow{2}{*}{$\begin{array}{l}\text { Neither } \\
\text { Agree/ } \\
\text { Disagree } \\
\text { N }(\%)\end{array}$} & \multirow{2}{*}{$\begin{array}{l}\text { Disagree } \\
\text { N }(\%)\end{array}$} & \multirow{2}{*}{$\begin{array}{l}\text { Strongly } \\
\text { Disagree } \\
\mathrm{N}(\%)\end{array}$} \\
\hline & & & & & \\
\hline I think that the retractable syringes are useful & $4(40)$ & $2(20)$ & $1(10)$ & $2(20)$ & $1(10)$ \\
\hline The retractable syringes is easy to use & $1(10)$ & $2(20)$ & $4(40)$ & $1(10)$ & $2(20)$ \\
\hline $\begin{array}{l}\text { I do not need a specific training to use the } \\
\text { retractable syringe }\end{array}$ & $2(20)$ & $3(30)$ & $2(20)$ & $2(20)$ & $1(10)$ \\
\hline The retractable syringe can be used with both hands & $2(20)$ & $3(30)$ & $1(10)$ & $0(0)$ & $2(20)$ \\
\hline The syringe safety mechanism works in a satisfactory manner & $1(10)$ & $3(30)$ & $3(30)$ & $2(20)$ & $0(0)$ \\
\hline It is easy to know when the safety mechanism is activated & $1(10)$ & $6(60)$ & $3(30)$ & $0(0)$ & $0(0)$ \\
\hline $\begin{array}{l}\text { The retractable syringe permits a good view of the injected } \\
\text { substance }\end{array}$ & $1(10)$ & $4(40)$ & $2(20)$ & $2(20)$ & $0(0)$ \\
\hline $\begin{array}{l}\text { An injection with the retractable syringe takes more time than } \\
\text { the traditional/standard version }\end{array}$ & $3(30)$ & $3(30)$ & $2(20)$ & $1(10)$ & $0(0)$ \\
\hline $\begin{array}{l}\text { Using retractable syringes protects the person who shares my } \\
\text { living quarters }\end{array}$ & $7(70)$ & $2(20)$ & $0(0)$ & $0(0)$ & $0(0)$ \\
\hline The number of syringes dispensed by the nurse is adequate & $4(40)$ & $3(30)$ & $2(20)$ & $1(10)$ & $0(0)$ \\
\hline $\begin{array}{l}\text { After I am released, I would like to continue using these type } \\
\text { of syringes }\end{array}$ & $1(10)$ & $3(30)$ & $2(20)$ & $3(30)$ & $0(0)$ \\
\hline
\end{tabular}

demonstrated by the mixed responses concerning need for specific training, ability to use syringe with either hand, safety mechanism and view of the injection substance (Table 2).

In qualitative follow-up, one (10\%) participant complained that retractable syringes were heavier than normal. Three users $(30 \%)$ complained also about the needle sharpness, describing that injections were more painful or more difficult, comparing the feeling to "injections with used needles." They noted that if the injection failed, they actually lost the product (drug), because they needed to break the syringe to recover it (no "second chances"). A participant pointed out that they could reuse syringes if they did not depress the plunger completely. IDU expressed the difficulty in adjusting the filter and adaptor to the syringe, making the preparation of the injection longer. However, $40 \%$ of the users agreed that they would use retractable NSP syringes outside prison (10\% "strongly agreed", $30 \%$ "agreed", $20 \%$ "neither agreed nor disagreed", $30 \%$ "disagreed" and $10 \%$ didn't answer, Table 2).

Description of PO and HS Knowledge and Perceptions (Table 3)

We interviewed $72 \mathrm{PO}$ and $21 \mathrm{HS}$. Both groups thought that infection risk was an important issue for inmates, HS (95.4\%), PO (88.4\%); they agreed on reduction of overcrowding as a method to address risk, HS (66.7\%), PO (54.6\%); PO were aware of the use of drugs in prison- $79 \%$ agreed that smoked drugs are used in the prison and $61 \%$ of them agreed with the statement that IV drugs were being used. HS perceptions were slightly higher: $90 \%$ thought that smoked drugs were currently used, and $80 \%$ had this opinion about injection drugs. Overall, $87.5 \%$ of the PO responded positively that regular training on this subject was important and needed, similar to HS (91\%). 
Table 3 Comparing responses about harm reduction programs, between prison officers and prison healthcare staff (responded "yes" or "absolutely")

\begin{tabular}{|c|c|c|}
\hline Questionnaire statement & $\begin{array}{l}\text { Prison } \\
\text { officers } \\
\text { N (\%) }\end{array}$ & $\begin{array}{l}\text { Health } \\
\text { staff } \\
\mathrm{N}(\%)\end{array}$ \\
\hline Prison staff are well taught and informed about the risk for infectious diseases (ID) & $36(50)$ & $20(95)$ \\
\hline ID risk is an important issue for prison staff & $65(90.2)$ & $10(47.7)$ \\
\hline ID risk is an important issue for inmates & $61(88.4)$ & $20(95.4)$ \\
\hline The most efficient method to reduce ID risk is to reduce overcrowding at this prison & $37(54.6)$ & $14(66.7)$ \\
\hline Illegal drug use by sniffing or smoking is common among inmates at this prison & $53(79.1)$ & $18(90)$ \\
\hline Illegal drug use by IV is common among inmates at this prison & $39(61)$ & $15(78.9)$ \\
\hline $\begin{array}{l}\text { Offering sterile injection material to IDU in the community setting is an effective way to } \\
\text { reduce the transmission of viral hepatitis }\end{array}$ & $51(73.9)$ & $21(100)$ \\
\hline $\begin{array}{l}\text { Offering sterile injection material to IDU while in this prison is an effective way to } \\
\text { reduce the transmission of viral hepatitis }\end{array}$ & $49(71)$ & $21(100)$ \\
\hline $\begin{array}{l}\text { Offering OST in the community setting to individuals who are opioid dependent is an } \\
\text { effective way to reduce the transmission of viral hepatitis }\end{array}$ & $48(73.8)$ & $21(100)$ \\
\hline $\begin{array}{l}\text { Offering OST in this prison setting to individuals who are opioid dependent is an } \\
\text { effective way to reduce the transmission of viral hepatitis }\end{array}$ & $47(70.2)$ & $21(100)$ \\
\hline I feel that IDU could use a syringe as a weapon, against me & $65(90.3)$ & $2(9.6)$ \\
\hline I believe that offering sterile injection to IDU, encourages and promotes more drug use & $54(76.1)$ & $1(4.8)$ \\
\hline $\begin{array}{l}\text { I think that, being in this line of work, I have a higher chance of being infected with } \\
\text { tuberculosis, than with HIV or hepatitis }\end{array}$ & $37(52.8)$ & $13(61.9)$ \\
\hline $\begin{array}{l}\text { Regular education and training on different aspects of ID is important for all the staff } \\
\text { working at this prison }\end{array}$ & $63(87.5)$ & $19(90.5)$ \\
\hline
\end{tabular}

Half of the PO stated that they were well trained and had information about the risks of transmission of infectious diseases, compared to $95 \%$ of HS. The majority of PO were concerned by the risk of acquiring an infectious disease in prison posed for themselves ( $90.2 \%$ agreed this was a risk), while the HS considered themselves less exposed (47.7\%).

Concerning the efficacy of harm reduction measures, $74 \%$ of PO agreed that NSP are efficient in the community while $100 \%$ of HS had this opinion. For prison NSP, $71 \%$ of PO agreed with their utility while $100 \%$ of HS supported prison NSP. The differences between PO and HS were similar in reference to community and prison OST with $100 \%$ HS agreeing with OST measures.

Despite the fact that no aggression with a syringe has been reported in this setting (Rieder, 2009; Services and of Canada, 2003), $90 \%$ of PO agreed with the statement that syringes could be misused as weapons; only $10 \%$ of HS expressed this perception. Seventy-seven percent of $\mathrm{PO}$ agreed that providing sterile syringes might increase drug use in prison, whereas only $5 \%$ of HS agreed with this statement.

\section{Discussion}

In our study, NSP with retractable syringes was perceived as an acceptable alternative for incarcerated injection drug users, although there were some technical caveats among users. They complained about difficulties due to the weight of the syringe and needle quality, as well as the difficulty to install and use the syringe filter. Of the 98 questionnaires distributed to PO 
and HS, $70 \%$ of PO and $100 \%$ of HS thought that harm reduction policies like NSP were an effective means to reduce the risk of BBV infections. However, $90.3 \%$ of PO were still concerned about the use of soiled syringes as weapons.

\section{IDU Experiences}

Preliminary evidence about retractable devices in NSP is concerning, as many user issues have yet to be acknowledged in studies (Fry, 2006). There is a need to engage in consultation and partnership in any research that involves IDU, and test empirically the impact of introducing new devices on a range of factors. In this case, these factors include syringe disposal practices, community perceptions (prison worker and staff perceptions in this prison case setting), the risk of needle stick injury, and syringe sharing practices among injection drug users. Ensuring acceptability by injection drug users is essential in maintaining NSP effectiveness (Kermode et al. 2003).

In our case, we found that there is much room for improvement. The fact that many syringes were used without filters is a problem in terms of harm reduction, considering the utility of the filter in avoiding injection of insoluble particles, which can lead to embolism or talcosis. Another possible reason explaining why filters were not used, is user fear of losing drug between the different membranes. This fear was reinforced in discussions of the safety mechanism itself, which they stated did not allow for "second chances" if the user missed the injection. IDU also stated that the syringe felt heavier and that the new needle made the injection more painful. Thus improvements to be made in the material include: better quality needles, lighter syringes, and adapted filters, which are easier and quicker to use.

Encouragingly, $90 \%$ of the IDU strongly agreed that retractable devices could reduce the risk of transmission of infectious disease. IDU considered retractable syringes as an acceptable alternative, despite equipment imperfections, particularly because they thought "using retractable NSP devices helps to protect others from potential infectious disease."

However, during the trial period, we noted a reduction in the return of used syringes compared to 2009: a return rate of $70 \%$, compared to $83.2 \%$ in the pre-study NSP (Wolff, 2010). Under the criteria established by WHO in collaboration with UNODC and UNAIDS, about 200 syringes per injection user per year reflects a high level of availability (Arnaud et al. 2011)- this translates to about 100 syringes per user for the 6-7 month study period observed here (as an ideal number). Given the 28 IDU enrolled into the NSP, the returned number of syringes is sub-par. Retractable devices were also returned dismantled, which poses the question as to what other functions they carried.

\section{Staff NSP Perceptions}

Previous reports have proposed that engaging prison staff more often in NSP development will address the opposition of correctional authorities (Mogg and Levy 2009). By understanding the views and the underlying motivations of those who oppose NSP or NSP innovations, it will be far easier to influence perceptions. As stated previously, "involving all stakeholders, especially prison authorities, creates a sense of ownership of whatever solution is devised and therefore increases the chances of the intervention succeeding" (Mogg and Levy 2009). Since the inception of NSP at Champ-Dollon, there has never been a case of a syringe used as a weapon. But despite more than 15 years of experience without incident, NSP is still perceived as potentially dangerous by the PO. This perspective was an important finding of this study.

Although our limited cohort is too small to look for differences between PO and HS perceptions, we describe a general view regarding the use of syringes as weapons, the risk of 
being infected in the prison, the level of formation concerning infectious diseases transmission, the efficiency of harm reduction measures (particularly NSP), and whether distribution of syringes increases drug consumption in prison. Overall, evaluation of NSP was positive. Given these findings, the dispensation of preventive messages and trainings at regular intervals concerning infectious diseases (while highlighting PO and HS perceptions and addressing the gaps in knowledge base) will be a way to improve the understanding of harm reduction programs and their need to be implemented in prisons (true cost and benefit ratio).

\section{Limitations}

Firstly this is an observational, descriptive study with a low number of participants, which may limit generalization to other settings. Nevertheless, we believe that this unique study sheds some insight into important issues from the prisoner and staff perspective. A possible explanation for the low NSP user turnout for the study is that there may not have been enough information disseminated about the program, although efforts were made on many front to ensure prisoner awareness. As well, perhaps the interval between syringe requests and distribution (even if short, in general only a few hours) or the need for face-to-face distribution with a medical provider (stigma) was as an obstacle for the drug users. The subsequent dropout was primarily due to early liberation of participants. The pre-trial detention setting makes it difficult to plan interviews, due to the incertitude of prisoners release status.

\section{Take-home Messages}

In general, very little literature about prison NSP incorporates the acceptability, knowledge and attitudes of users and prison stakeholders (Mogg and Levy 2009; Ferrer-Castro et al. 2012). The introduction of retractable needles into NSP will result in a decrease in syringe sharing, only if accepted by injection drug users as an equally good alternative (Kermode et al. 2003). Here, the trial group of IDU accepted retractable syringes. Nevertheless improvements are necessary to increase the use of those syringes, specifically in the filtering and injecting process. Improving retractable devices in their quality and ease of use can increase their acceptance.

For PO working in a prison with a well-functioning NSP, a perceived fear that syringes are used as weapons and/or encourage drug use remains, despite general acceptance. Whether retractable syringes can also help ease security concerns of this prison administration remains to be seen in further trials. The introduction and innovation of NSP in prisons, as in the community, is a step forward in a worldwide movement of addressing health disparities among prisoners, especially as the prison population globally expands (Jürgens et al. 2009).

Disclosure This study received financial support from Unitract and the University Hospitals of Geneva

\section{References}

Addiction Suisse. (2013, May 17). Infections par VIH dues à l'injection de drogues. Retrieved from: http://www. sucht-info.ch/fr/faits-et-chiffres/heroine/effets-et-risques/infections-par-vih/.

Arnaud, S., Jeannin, A., \& Dubois-Arber, F. (2011). Estimating national-level syringe availability to injecting drug users and injection coverage: Switzerland, 1996-2006. International Journal of Drug Policy, 22(3), 226-32.

Bruce, R., \& Schleifer, R. (2008). Ethical and human rights imperatives to ensure medication-assisted treatment for opioid dependence in prisons and pre-trial detention. International Journal of Drug Policy, 19, 17-23. 
CDC, Centers for Disease Control and Prevention. (2001, August). Drug use, HIV and the criminal justice system. Retrieved from: http://www.cdc.gov/idu/facts/criminaljusticefactsheet.pdf.

Correctional Services of Canada. (2003). Infectious diseases prevention and control in Canadian federal penitentiaries, 2000-01 : a report of the Correctional Service of Canada's infectious diseases surveillance system. Ottawa: Correctional Service Canada.

Degenhardt, L., Mathers, B., Vickerman, P., Rhodes, T., Latkin, C., \& Hickman, M. (2010). Prevention of HIV infection for people who inject drugs: why individual, structural, and combination approaches are needed. The Lancet, 376, 285-301.

Des Jarlais, D. C. (1998). "Single-use" needles and syringes for the prevention of HIV infection among injection drug users. Journal of Acquired Immune Deficiency Syndromes and Human Retrovirology, 18 Supplement 1, S52-6.

Dolan, K. (2000). Surveillance and prevention of hepatitis C in Australian prisons: a discussion paper. National Drug \& Alcohol Research Centre, Technical report \#95. Retrieved from: http://ndarc.med.unsw.edu.au/sites/ default/files/ndarc/resources/TR.095.PDF

Dolan, K., Rutter, S., \& Wodak, A. D. (2003). Prison-based syringe exchange programmes: a review of international research and development. Addiction, 98, 153-8.

European Monitoring Centre for Drugs and Drug Addiction . (2004). Annual report on the state of the drug problems in the European Union and Norway. Retrieved from: http://emcdda.europa.eu.

European Monitoring Centre for Drugs and Drug Addiction. (2011). Annual report on the state of the drug problems in Europe. Retrieved from: http://emcdda.europa.eu.

European Monitoring Centre for Drugs and Drug Addiction. (2011). Statistical Bulletin: Drug Users in Prison (DUP). Tables 3 and 105. Retrieved from: http://emcdda.europa.eu/stats11.

Federal authority of the Swiss Conferederation. (2011). Loi fédérale sur les stupéfiants et les substances psychotropes, Etat le 1 juillet 2011. Retrieved from: http://www.admin.ch/ch/f/rs/812_121.

Ferrer-Castro, V. et al. (2012). Evaluacion del Programa de Intercambio de Jeringuillas en el Centro Penitenciario de Pereiro de Aguiar (Ourense): diez anos de experiencia. Revista Española de Sanidad Penitenciaria, 14, $3-11$.

Fry, C. L. (2006). Letter-Australian resources for ethical participatory processes in public health research. Journal of Medical Ethics, 32, 186.

Global Comission on Drug Policy. (2013). The Negative Impact of the War on Drugs on Public Health: The Hidden Hepatitis C Epidemic. Retrieved from: http://www.globalcomissionondrugs.org/hepatitis/gcdp_ hepatitis_english.pdf.

Harm Reduction International. (2010, April). The Global State of Harm Reduction 2010: Key issues for broadening the response. Retrieved from: http://www.ihra.net/contents/535.

Jürgens, R. (2007). Interventions to adress HIV in prisons : Needle and syringe programmes and decontamination strategies. Geneva, Switzerland: WHO, UNODC, UNAIDS. Retrieved from: http://www.unodc.org/ documents/hiv-aids/EVIDENCE\%20FOR\%20ACTION\%202007\%20NSP.pdf.

Jürgens, R., Ball, A., \& Verster, A. (2009). Interventions to reduce HIV transmission related to injecting drug use in prison. The Lancet Infectious Diseases, 9, 57-66.

Jürgens, R., Nowak, M., \& Day, M. (2011). HIV and incarceration: prisons and detention. Journal of the International AIDS Society, 14, 26.

Kermode, M., Harris, A., \& Gospodarevskaya, E. (2003). Introducing retractable needles into needle and syringe programmes: a review of the issues. International Journal of Drug Policy, 14, 233-9.

Larney, S. (2010). Does opioid substitution treatment in prisons reduce injecting-related HIV risk behaviours? A systematic review. Addiction, 105, 216-23.

Lines, R., Jurgens, R., Betteridge, G., Stover, H., Laticsvschi, D. \& Nelles, J. (2006, April 30). Prison Needle Exchange: Lessons from A Comprehensive Review of International Evidence and Experience, 2004. (2nd ed.) Canadian HIV/AIDS Legal Network. Retrieved from: http:/www.aidslaw.ca/publications/interfaces/ downloadFile.php?ref=1173.

Mogg, D., \& Levy, M. (2009). Moving beyond non-engagement on regulated needle-syringe exchange programs in Australian prisons. Harm Reduction Journal, 6, 7.

Mumola, C. J. (1999). Substance abuse and treatment of state and federal prisoners, 1997. Retrieved from: http:// www.iapsonline.com/sites/default/files/Substance $\% 20$ Abuse $\% 20$ and $\% 20$ Treatment $\% 20$ of $\% 20$ State $\%$ 20 and\%20Federal\%20Prisoners, \%201997.pdf.

Office Fédéral de la Statistique. (2010) Statistiques des condamnations pénales. Retrieved from : http://www.bfs. admin.ch.

Rieder, J. P. (2009) Programme d'échange de seringues pour usagers de drogues par voie intra-veineuse dans une prison préventive à Genève. Le Flyer Bulletin de liaison des Centres de Soins Spécialisés pour Toxicomanes et médecins relais rds, pharmaciens d'officine, ECIMUD et structures de soins auprès des usages de drogue. Retrieved from : http://www.rvh-synergie.org/documents/Flyer37.pdf. 
Stark, K., Herrmann, U., Ehrhardt, S., \& Bienzle, U. (2006). A syringe exchange programme in prison as prevention strategy against HIV infection and hepatitis B and C in Berlin, Germany. Epidemiology and Infectiology, 134, 814-9.

Thiede, H., Romero, M., Bordelon, K., Hagan, H., \& Murrill, C. S. (2001). Using a jail-based survey to monitor HIV and risk behaviors among Seattle area injection drug users. Journal of Urban Health, 78, 264-78.

Todts, S., Hariga, F., Pozza, M., Leclercq, D., Glibert, P., \& Micalessi, M. I. (2007). Usage de drogues dans les prisons belges. Monitoring des risques sanitaires 2006. Bruxelles (Belgium): Service public fédéral Justice.

Whitby, M., McLaws, M. L., \& Slater, K. (2008). Needlestick injuries in a major teaching hospital: the worthwhile effect of hospital-wide replacement of conventional hollow-bore needles. American Journal of Infection Control, 36, 180-6.

World Health Organization. (2004). Effectiveness of Sterile Needle and Syringe Programming in Reducing HIV/ AIDS Among Injecting Drug Users. Geneva, Switzerland: WHO. Retrieved from: http://www.who.int/entity/ hiv/pub/prev_care/effectivenesssterileneedle.pdf.

Wodak, A., \& Cooney, A. (2006). Do needle syringe programs reduce HIV infection among injecting drug users: a comprehensive review of the international evidence. Substance Use \& Misuse, 41, 777-813.

Wolff, H. (2010). Personal communication regarding occupancy rate of Geneva prison to prison medical attendings. In: Barro J, editor. 2010.

Wolff, H., et al. (2011). Health problems among detainees in Switzerland: a study using the ICPC-2 classification. BMC Public Health, 11, 245. 